\title{
A ESCRITURA DE GUNTER EICH ENQUANTO EPIFANIA
}

Eloá Di Pierro Heise

"Sou partidário do silêncio, talvez um problema da minha geração. Minha tarefa inconsciente sempre foi traduzir o silêncio necessáric em diálogo, em palavras, e de tal modo que não perca seu caráter de silêncio (IV,441)" (1). Essas afirmações de Günter Eich, extraídas de sua Abgekürzte Dramaturgie des Hörspiels (Dramaturgia Resumida da Radiopeça-1968), atestam em que medida o autor pode ser encaixado dentro de uma das tendências mais características da literatura do nosso tempo, uma "poética do silêncio", que reflete o impasse diante do qual a literatura contemporânea foi coiocada em sua busca exarcebada de atingir a esfera do absoluto através da sugestão verbal.

Mesmo que a tentação progressiva do inatingível procure traduzir em linguagem o que as palavras não conseguem dizer, descortinando-se aí o beco suicida do silêncio, Eich acaba atenuando, se não quase suprimindo, seu pessimismo crítico em face de uma realidade que perdeu sua unidade paradisíaca atraves de seu otimismo pela forma. A tentativa de "traduzir o silêncio necessário em linguagem, em palavras, e de tal modo que não perca seu caráter de silêncio", implica muito mais ausência que presença, mas permite também conotar sua obra de um novo sentido, onde o roçar dos limites àa sensação de p'enitude decorre da constante procura de encontro entre o eu e o mundo através da linguagem. Para a mobilidade inquieta do autor, a obra perfeita torna-se inviável e só pode satisfazer seu anseio de infinito pela aproximação constante. Contudo, sendo impossível a visão de totalidade, restam apenas relances de luz, momentos epifânicos de revelação que são novamente diluídos pelo tempo.

(1) - As citações das obras de Günter Eich, extraídas dos quatro volumes que compõe a coletânea das Obras Coligidas, Frankfurt am Main, Suhrkamp Verlag, 1973, serão indicadas por um algarismo romano (número do volume da coletânea) e um arábico (número da página do referente volume). 
Quando nos referiamos à escritura de Eich, partimos de um pressuposto. Tal palavra é tomada no sentido que lhe deu seu criador Roland Barthes: "A escritura é com efeito em todos os níveis a fala de um outro (...)" (2). O escritor destaca das falas primeiras que lhe fornece o mundo uma fala segunda, fazendo de sua ficção um meio de conhecimento. E como se em lugar de escrever, o autor descrevesse, deixando à tona o que parecia inexprimível. Retirando "da língua do mundo, que é pobre ( ) uma outra fala, uma fala exata, preenche a tarefa da arte: inexprimir o exprimivel" (3).

Günter Eich, escritor rebelde, irreverente e anárquico, crítico que com seu humor ácido e corrosivo procura desmascarar toda a verdade "dirigida", é dotado de uma veia satírica que não poupa nem sequer a si mesmo. Engaja profundamente sua obra nas perguntas do mundo, mas cessa esse engajamento na medida em que qualquer tipo de doutrina, partido ou cultura lhe insufle uma resposta definitiva. Esse mesmo Eich que afirma: "espero que a obra permaneça e o comentário desapareça (IV, 404)", que se recusa sistematicamente a falar de si e de "suas coisas", que não perde oportunidade para desqualificar o estudo dos críticos e esvaziar de sentido as honrarias que lhe foram prestadas, mostra-se profundamente comprometido com a busca do ser sob forma de linguagem.

Interiorizando o escrever como destino absoluto, o escritor vê na linguagem a mediadora entre o poeta e o mundo, o instrumento através do qual a realidade deve ser procurada e reconstituída: "Escrevo poesias para me orientar na realidade. Eu as considero como pontos trigonométricos, como bóias que marcam o curso em uma superfície desconhecida. Só através do ato de escrever as coisas adquirem, para mim, realidade. Ela não é minha premissa, mas minha meta. Preciso primeiro constituí-la (IV, 441)" Escrever seria portanto uma maneira de reconstituir o mundo, mas esse ato de criação só adquire pertinência na medida em que se traduz em forma: "Tudo que ganhou uma forma, vai ser empregado em um sentido mais elevado, torna-se também aplicável a esferas as quais possivelmente seu criador nem imaginou (IV, 437)" O poeta, vendo na forma a essência da criação poética, está, paralelamente, consciente da limitação dessa forma, pois a linguagem aponta para os objetos, sem nunca os alcançar; o sentido do discurso articula-se na medida em que a palavra substitui os objetos sem ser idêntica a eles: "Sou escritor, isso não é apenas uma profissão, mas a decisão de

\footnotetext{
1970 , p. 20

(2) - Barthes, R: Crítica e Verdade, São Paulo, Ed. Perspectiva, (3) - Idem, p. 20
} 
ver o mundo como linguagem. Linguagem propriamente dita parece-me ser aquela em que a palavra e o objeto coincidem. Trata-se de traduzir dessa linguagem que se encontra à nossa volta, mas que simultaneamente não é existente. As traduções mais bem sucedidas são as que mais se lhe aproximam e que alcançam o mais elevado grau de realidade (IV, 441)"

Com relação aos objetos a linguagem é basilarmente irrealista, pois representa um estado intermediário entre as coisas e as palavras. Perseguindo a identidade entre os signo e o objeto, Eich questiona $o$ ato de escrever enquanto nomear. A realidade que tenta instaurar através de sua criação, não significa uma cópia das coisas, mas a indagação das possibilidades da linguagem em sua limitação; uma torma de explorar de maneira profunda a capacidade de veiculação desse meio de expressão.

A escritura de Eich, "inexprimindo o exprimível", busca um "texto primevo" que se encontra a nossa volta e ao mesmo tempo se mostra inatingível. Sem produzir a sensação de reconhecimento da realidade em seu aspecto total, sua escritura apresenta o mundo muito mais como visão, onde a palavra torna-se um meio de experimentar o devir do objeto, prolongando o ato percepção. Esse objeto é resgatado de seu destino circunstancial, destacado do contexto e adquire um valor renovado pela visão criadora do poeta. Sob esse aspecto, caracteristicamente poético, a linguagem ultrapassa os limites de forma de expressão, para adquirir o caráter de epifania, entendida como a procura constante de um instante de reconhecimento. Contudo, o devir do objeto prolongado em sua percepção não chega a atingir o momento excepcional de expressão, pois o autor transforma sua busca da linguagem em processo dinâmico, apontando sempre para a ruptura entre a palavra e o mundo.

Para Eich, a epifania enquanto linguagem implica um processo operativo de criação na busca constante de revelação do real. Visando a um foco transcedente, a linguagem lança-se a uma permanente renovação, pois um texto só vai repercutir socialmente de maneira ativa se houver uma constante mudança na forma. Fazendo da palavra um instrumento de indagação e crítica da realidade, torna-se necessário que o dizer do poeta seja constantemente posto em causa, para que possa ter ressonância e consiga preencher sua função de oposição: "( ) parece-me sobretudo importante que a modificação e o desenvolvimento se processem não através do conteúdo, mas através da linguagem; devemos esforçar-nos continuamente para não deixar que a linguagem se enrijeça, para conservá-la de tal maneira que não possa ser utilizada por poderes quaisquer, que 
permaneça uma linguagem em constante movimento e que toda estrutura rígida seja logo novamente rompida e não utilizável na política, enfim, que a linguagem permaneça de tal forma que possa servir para transformar o mundo, que não seja petrificada (IV, 408)"

A epifania apresenta-se, assim, como a possibilidade de tentar desvendar a verdade que existe sob a aparência das coisas, como constante procura de revelação e reconhecimento. A inexistência de um contato absoluto admite apenas uma aproximação infinita que implica movimento constante.

As noções poéticas de Eich e sua criação linterária fundem-se e confundem-se em um todo orgânico, sua obra é um documento que concretiza suas concepções sobre a arte de escrever: uma criação poética a respeito de sua própria poética. Essa fiç̧ão unificada por forte traço de coerência converge para a tematização do fenômeno da epifania, que ultrapassa, assim, o nível da linguagem, para ser in. tegrado à visão do mundo.

Do ponto de vista teórico os textos de Eich se amoldam ao esquema de uma narrativa modelo, onde a busca representa o eixo central:

1 - Equilíbrio inicial relativo a realidade imanente.

2 - Intervenção de um acontecimento inusitado (etapa onde ocorre a epifania)

3 - Tal acontecimento vai provocar uma longa busca.

4 - Atinge-se um segundo equilíbrio, também relativo ao mundo cotidiano, semelhante no primeıro, mas não idêntico.

Mesmo dentro dessa simplificação da organicidade dos textos que compõe o complexo universo seınântico do autor, nota-se como a própria tematização do ato de buscar adquire aspectos profundamente dinâmicos. Depois de ter vivenciado nor segundos a súbita revelação da verdade, a personagem procura reviver esse instante de plenitude. Na radiopeça Sabeth (1951), ocorreu a vinda de um enorme e estranho pássaro, uma ave que parece estar ligada a um mundo regido por uma outra "verdade", onde os nossos conceitos rigidos entre o que é e o que não é, perdem sua validade. A presença do corvo faz com que todos aqueles que vivenciaram sua chegada sintam a proximidade "de uma grande felicidade, tão próxima como nunca, mas, paralelamente, inatingível"

Em Das Jahr Lazertis (1953), Paul, o protagonista, sai à procura de uma palavra que ouvira durante o sono pela janela entrea- 
berta de seu quarto. No momento da prolação desse nome, chegou-se, por segundos, à compreensão do mundo à sua transparência. O protagonista lança-se à aventura de encontrar novamente a cifra de todes os significados. Assim, um objeto qualquer, num instante banal, consegue a suspensão do tempo cronológico e cristaliza a realidade. A epifania representa um momento de visão, que não sendo explicado racionalmente, surge como fonte de revelação.

De forma abrangente, podemos analizar o fenômeno da epifänia enquanto tema especificando o relacionamento dialético entre dois elementos: $e u$ e o mundo. Nosso esquema racional de concepção do mundo apresenta o homem como um sujeito, em relação com um mundo que lhe é exterior e que adquire o estatuto do objeto (outro) A anulação das fronteiras entre o sujeito e o objeto é parte da ocorrência epifânica.

Produz-se um acontecimento que nos é familiar, mas, que coni sua força inusitada, faz com que se experimente a sensação de uma revelação e reconhecimento de verdades que parecem inexplicáveis. Assim posto, pode-se questionar as possíveis relações entre todos os elementos do mundo. Numa indagação mais profunda e abstrata, a epifania que brota dessa percepção de uma realidade pertubadora, emergente de situações as mais banais e cotidianas, implica o transcender dos limites entre o físico e o mental, entre a matéria e o espírito (4)

$\mathrm{Na}$ medida em que se percebe a ruptura dos limites de nossa realidade e mundos originalmente estanques se interpenetram, a palavra se desliga do objeto que supostamente designa: além do sentido primeiro evidente, pode-se sempre perceber um sentido mais profundo. Com a expressão dos momentos epifânicos, surgem as imagens, via analógica de que o artista lança mão para se aproximar de uma apreensão da realidade totalizante. Essas imagens, substâncias poéticas de seus textos, promovendo a percepção da literariedade, conseguem atribuir existência à palavra sem o apoio das coisas. Multiplicam-se os significados dos nomes sem os preencher ou esgotar totalmente.

Percebe-se, aí, em que medida a obra do autor é uma reflexão sobre si mesma, uma criação poética a respeito de sua própria poética. Do mesmo que a linguagem como forma de mediação entre o escritor e o mundo conduz e limita a busca das essências que nunca se concretiza, na ocorrência do fenômeno epifânico percebe-se também sem-

(4) - Cf. Todorov, T: Introdução à Literatura Fantástica, São Paulo, Ed. Perspectiva, 1975, pp. 121-124. 
pre o sentido de uma revelação em aberto. O nada e o tudo acontecem em um momento inesperado. Nesse instante de atemporalidade, podem-se roçar os limites de uma outra realidade, contudo, esses contatos que chegam a ocorrer por segundos, são novamente destruídos. Retorna-se à busca infinda: "( ) Algumas vezes tenho a impressão de que a escuridão clareia por um momento ( ) Nada, ou tam bém muito. Perpassou-me como uma luz. (...) Então desapareceu novamente. Foi um encantamento grande e repentino. Eu soube tudo (II, 378)"

Dentro do mundo eichano o figurante apenas se aproxima de uma verdade inatingível; sua busca é apresentada como infrutífera. A desilusão da procura do significado da existência vai reconduzir o homem a fatos do cotidiano, que lhe estão destinados como realidade palpável e compreensível. As personagens resignam-se à crença de que revelação sempre lhes escape. O caminho que leva à verdade é uma experiência individual, interior e inexplicável, que dá sinais efetivos de sua existência muito mais no prenúncio, que implica pergunta, do que no anúncio, que subentende resposta.

A obra de Eich representa, assim, a reiteração de uma indagação maior, onde o vazio, em sua eterna procura que não pode ser exaurida, vai adquirir o valor e a equivalência do pleno. Algo sempre foge na concretização da verdade, apesar de que por instantes se vislumbre uma possibilidade de encontro, projetada insistentemente através de momentos epifânicos. 